\title{
Cerebral palsy and placental infection: a case-cohort study Rasiah Vigneswaran ${ }^{1}$, Stacey J Aitchison ${ }^{2}$, Helen M McDonald ${ }^{3}$, T Yee Khong ${ }^{4}$ and Janet E Hiller*2
}

\begin{abstract}
Address: ${ }^{1}$ Department of Neonatology, Women's and Children's Hospital (WCH), 72 King William Road, North Adelaide, South Australia, Australia 5006, ${ }^{2}$ Department of Public Health, University of Adelaide, 5005 Australia, ${ }^{3}$ Department of Microbiology and Infectious Diseases, Women's and Children's Hospital, 72 King William Road, North Adelaide, South Australia, Australia 5006 and ${ }^{4}$ Department of Histopathology, Women's and Children's Hospital 72 King William Road, North Adelaide, South Australia, Australia 5006
\end{abstract}

Email: Rasiah Vigneswaran - ; Stacey J Aitchison - stacey.aitchison@bigpond.com; Helen M McDonald - mcdonaldh@wch.sa.gov.au; T Yee Khong - yee.khong@adelaide.edu.au; Janet E Hiller* - janet.hiller@adelaide.edu.au

* Corresponding author

Published: 27 January 2004

BMC Pregnancy and Childbirth 2004, 4:I
Received: 08 September 2003

Accepted: 27 january 2004

This article is available from: http://www.biomedcentral.com/I47/-2393/4/I

(C) 2004 Vigneswaran et al; licensee BioMed Central Ltd. This is an Open Access article: verbatim copying and redistribution of this article are permitted in all media for any purpose, provided this notice is preserved along with the article's original URL.

\begin{abstract}
Background: The association between cerebral palsy in very preterm infants and clinical, histopathologic and microbiological indicators of chorioamnionitis, including the identification of specific micro-organisms in the placenta, was evaluated in a case-cohort study.

Methods: Children with a diagnosis of cerebral palsy at five years of age were identified from amongst participants in a long-term follow-up program of preterm infants. The comparison group was a subcohort of infants randomly selected from all infants enrolled in the program. The placentas were examined histopathologically for chorioamnionitis and funisitis, and the chorioamnionic interface was aseptically swabbed and comprehensively cultured for aerobic and anaerobic bacteria, yeast and genital mycoplasmas. Associations between obstetric and demographic variables, indicators of chorioamnionitis and cerebral palsy status were examined by univariate analysis.

Results: Eighty-two infants with cerebral palsy were compared with the subcohort of 207 infants. Threatened preterm labor was nearly twice as common among the cases as in the subcohort ( $\mathrm{p}<$ 0.01 ). Recorded clinical choroamnionitis was similar in the two groups and there was no difference in histopathologic evidence of infection between the two groups. $E$. coli was cultured from the placenta in $6 / 30(20 \%)$ of cases as compared with $4 / 85(5 \%)$ of subcohort $(p=0.01)$. Group B Streptococcus was more frequent among the cases, but the difference was not statistically significant.

Conclusions: The association between $E$. coli in the chorioamnion and cerebral palsy in preterm infants identified in this study requires confirmation in larger multicenter studies which include microbiological study of placentas.
\end{abstract}




\section{Background}

The rate of cerebral palsy amongst neonatal survivors born below 33 weeks is up to 30 times higher than among those born at term $[1,2]$. The etiology of this condition is poorly understood and current research focuses on the prenatal period. A number of epidemiologic studies have reported a relationship between maternal clinical chorioamnionitis and neurologic damage among very low birthweight infants [3-10]. This correlation is corroborated by experimental data [11].

Although most prior studies have used non-specific clinical measures of chorioamnionitis to provide retrospective information on infection [7], studies linking histopathologic indicators of chorioamnionitis with cerebral palsy point to infection of the chorioamnion as a potential cause. Investigations into the etiology of cerebral palsy among surviving very preterm infants have rarely examined the microbiology of the chorioamnion. Knowledge of the specific microorganisms involved is essential before preventive strategies such as screening and treatment of infection during pregnancy can be developed. This study examines clinical, histopathologic and microbiological indicators of chorioamnionitis, including the identification of specific micro-organisms in the placenta as risk factors for cerebral palsy among preterm infants.

\section{Methods}

A case-cohort study was conducted using the Women's and Children's Hospital (Adelaide, Australia) long-term follow-up program for the years 1984 to 1994 . The casecohort study design provides the advantages of a cohort study in that it allows the direct calculation of a risk ratio without either a rare disease assumption or, as in this case, the collection of full information on every member of a cohort. All cases of the condition of interest that arise within a defined cohort comprise the case group. Their exposure experience is compared with that of a randomly selected subset of the entire cohort. Thus exposure data in this study were ascertained on all cases of cerebral palsy and a subset of all preterm infants enrolled in the longterm follow-up program. The case-cohort study design allows for the efficient investigation of all cases of cerebral palsy within the target cohort and a sample of infants enrolled in the longterm follow-up program, without losing the advantage provided by the direct measurement of risk of cerebral palsy associated with placental infection, which would be assessed in a cohort study [12].

Pre-term infants are registered in the long-term follow-up program by hospital staff. Criteria for registration have changed over time; infants registered prior to 1992 had birthweights $\leq 1500$ grams. After 1992, only infants born at $\leq 29$ weeks gestation or $\leq 1000$ grams were eligible for long-term follow-up. This study only included infants enrolled in the program between 1984 and 1994 to ensure that sufficient calendar time had elapsed for all of them to undergo neuro-developmental assessment at five years of age.

Cerebral palsy was determined by assessment by a paediatrician and physiotherapist with expertise in neurodevelopment. In the Long-Term Follow-Up Unit, cerebral palsy is defined as disorder of movement and posture occurring due to central problems of the brain and is of early childhood onset; there should be some objective motor signs present - such as alteration of muscle tone, deep tendon reflexes or persistent puncture reflexes, alteration of balance and control and, in some individuals, presence of involuntary movements; other progressive neuromuscular disorders or insult to the brain that was acquired after 2 years of age were excluded. Every child diagnosed by neuro-developmental assessment at five years of age as having cerebral palsy and for whom antenatal data were available, was included as a case. If there was no diagnosis at 5 years of age, then a diagnosis of moderate or severe cerebral palsy at either three or four years of age was accepted. If a diagnosis was made at two years of age or less that was not confirmed at a later age, the child was not included as a case. Any child with a diagnosis of minimal cerebral palsy was excluded. Of 143 originally identified on the database we excluded children with a minimal diagnosis, two who were adopted, 12 retrievals who had no antenatal data, and 20 with a diagnosis of mild CP before 24 months of age that was not confirmed subsequently and two who were syndromic.

The comparison group was a subcohort randomly selected from the long term follow-up data base regardless of case status and covariate status and with antenatal data available ( 24 cases were also included in the sub-cohort). A random sample generator in Microsoft Excel was used to generate the subcohort selecting based on unit record number, which is a unique identifier for each infant. The subcohort was selected to represent the distribution of infants entered onto the Growth and Development Unit database under the two different admission criteria. A total of 1207 infants were admitted to the Growth and Development Program at the Women's and Children's Hospital between 1984 and 1994. Between 1984 and 1991, $920(76 \%)$ infants were admitted to the Long Term Follow-Up Program under the selection criterion of weighing $<1500 \mathrm{~g}$ at birth. Between 1992 and 1994, 287 (24\%) infants were admitted to the Growth and Development Unit under the selection criteria of $\leq 29$ weeks gestational age or $<1000 \mathrm{~g}$ at birth. Of the 240 infants selected for the subcohort, $182(76 \%)$ were born between 1984 and 1991, while 58 (24\%) were born between 1992 and 1994. Following the exclusion of children who were 
Table I: Demographic and obstetric characteristics of study population

\begin{tabular}{|c|c|c|c|c|}
\hline CHARACTERISTICS & Cases n (\%) & Sub-Cohort n (\%) & $\begin{array}{l}\text { Relative risk ( } 95 \% \\
\text { Confidence Intervals) }\end{array}$ & $P$ value \\
\hline Total & 82 & 207 & & \\
\hline \multicolumn{5}{|l|}{ Obstetric Factors } \\
\hline Primigravida & 27 (33\%) & 81 (39\%) & $0.81[0.55,1.19]$ & 0.29 \\
\hline Threatened preterm labor & $15(18 \%)$ & $18(9 \%)$ & $1.82[1.21,2.73]$ & $<0.01$ \\
\hline Pre-eclampsia & $8(10 \%)$ & $30(14 \%)$ & $0.69[0.36,1.30]$ & 0.25 \\
\hline $\begin{array}{l}\text { Severe intra-uterine growth restriction (as } \\
\text { in casenotes) }\end{array}$ & $13(16 \%)$ & $32(16 \%)$ & $1.00[0.61,1.64]$ & 1.00 \\
\hline Placental abruption & II (13\%) & $19(9 \%)$ & $1.37[0.83,2.24]$ & 0.22 \\
\hline $\begin{array}{l}\text { Preterm prelabor rupture of the } \\
\text { membranes }\end{array}$ & $32(39 \%)$ & $79(38 \%)$ & $1.02[0.71,1.48]$ & 0.90 \\
\hline Placenta previa & $6(7 \%)$ & $8(4 \%)$ & $1.53[0.83,2.83]$ & 0.18 \\
\hline Preterm labor & $37(45 \%)$ & $94(45 \%)$ & $1.04[0.72,1.49]$ & 0.83 \\
\hline \multicolumn{5}{|l|}{ Mode of delivery } \\
\hline Normal vaginal delivery & $25(30 \%)$ & $56(27 \%)$ & 1.00 & 0.37 \\
\hline Cesarean section & $47(57 \%)$ & $129(62 \%)$ & $0.83[0.56,1.24]$ & \\
\hline Forceps/Breech & $10(12 \%)$ & $22(11 \%)$ & $1.08[0.60,1.94]$ & 0.79 \\
\hline \multicolumn{5}{|l|}{ Neonatal Factors } \\
\hline \multicolumn{5}{|l|}{ Gestational age at delivery } \\
\hline$\leq 27$ weeks & $28(34 \%)$ & $54(26 \%)$ & I.87 $[0.94,3.70]$ & 0.07 \\
\hline 28-3I weeks & $46(56 \%)$ & $|2|(58 \%)$ & $1.47[0.75,2.85]$ & 0.26 \\
\hline$\geq 32$ weeks & $8(10 \%)$ & $32(16 \%)$ & 1.00 & \\
\hline $\begin{array}{l}\text { Gestational age at delivery weeks, median } \\
\text { (inter-quartile range) }\end{array}$ & $29(27-30)$ & $29(27-3 \mid)$ & $0.93[0.86,1.00]^{\mathrm{a}}$ & 0.06 \\
\hline $\begin{array}{l}\text { Birthweight, grams, median (inter-quartile } \\
\text { range) }\end{array}$ & I $100(880-1290)$ & $1170(970-1350)$ & $0.93[0.87,0.99]^{\mathrm{b}}$ & 0.03 \\
\hline Multiple gestation & $18(22 \%)$ & $58(28 \%)$ & $0.77[0.49,1.20]$ & 0.25 \\
\hline Male gender & 48 (59\%) & $104(50 \%)$ & $1.30[0.90,1.89]$ & 0.16 \\
\hline
\end{tabular}

a Relative risk for gestational age at delivery is for a I week increase b Relative risk for birthweight is for a $100 \mathrm{~g}$ increase

adopted and those who were transferred in, 207 infants were available for analysis.

Demographic, obstetric and laboratory data were collected from case note review and hospital databases. Obstetric data included threatened preterm labor which is defined as preterm labor that is subsequently suppressed and does not result in delivery. Placental swabs for microbiology were obtained aseptically by histopathology staff from the chorioamnionic membrane interface from 30 cases and 85 subcohort, and cultured for aerobic and anaerobic bacteria, yeasts and genital mycoplasmas, according to hospital guidelines which specified that placentas from gestations less than 34 weeks should be submitted for pathological examination $[13,14]$. Placental examination was performed in $54(65 \%)$ cases and 150 $(72 \%)$ subcohort. These slides were reviewed in 2001 by a histopathologist blinded to the cerebral palsy outcome and acute chorioamnionitis and funisitis were diagnosed using standard criteria [15].

Univariate analyses were undertaken examining associations between obstetric and demographic characteristics, clinical, histopathologic and microbiological indicators of chorioamnionitis and cerebral palsy status. Results of multivariable analyses are not presented. Given the complexity of causal pathways to cerebral palsy involving preterm birth [16], we considered it inappropriate to adjust (other than by stratified sampling), for gestation, which may be both an independent cause of cerebral palsy and on the pathway from infection to cerebral palsy.

\section{Results}

Eighty two infants with cerebral palsy ( 25 with quadriplegia, 14 with hemiplegia, 31 with diplegia, 2 with monoplegia, 10 other types) were compared with the subcohort of 207 infants. Eighty five percent of the infants with cerebral palsy and eighty four percent of infants in the comparison sub-cohort entered the follow-up database prior to 1992. The demographic and obstetric characteristics of the study population are shown in Table 1 . Over one quarter of infants was of multiple gestation. Threatened preterm labor was nearly twice as common among the cases as in the subcohort $(\mathrm{p} \leq 0.01)$. Preterm prelabor rupture of membranes, which carries an increased risk of infection, was frequent in both cases and subcohort. 
Table 2: Indicators of chorioamnionitis: clinical, histologic and microbiological

\begin{tabular}{|c|c|c|c|c|}
\hline & Cases & Sub-Cohort & $\begin{array}{l}\text { Relative risk ( } 95 \% \\
\text { Confidence Intervals) }\end{array}$ & $P$ value \\
\hline Clinical indicators & $\mathrm{n}=82$ & $\mathrm{n}=207$ & & \\
\hline Recorded clinical chorioamnionitis & $10(12 \%)$ & 27 (13\%) & $0.94[0.54,1.64]$ & 0.84 \\
\hline Maternal fever ${ }^{\mathbf{a}}$ & $21(26 \%)$ & $40(19 \%)$ & $1.26[0.84,1.87]$ & 0.26 \\
\hline Uterine tenderness & $13(16 \%)$ & $30(14 \%)$ & $1.13[0.69,1.82]$ & 0.63 \\
\hline Maternal tachycardia & $15(18 \%)$ & 49 (24\%) & $0.78[0.48,1.26]$ & 0.31 \\
\hline Fetal tachycardia & $11(13 \%)$ & $33(16 \%)$ & $0.87[0.5 \mathrm{I}, \mathrm{I} .49]$ & 0.62 \\
\hline $\begin{array}{l}\text { Elevated maternal C-reactive protein } \\
(>6 \mathrm{mg} / \mathrm{L}) / \mathrm{no} \text {. tested }\end{array}$ & $29 / 38(76 \%)$ & $49 / 78(63 \%)$ & $1.75[0.93,3.30]$ & 0.08 \\
\hline $\begin{array}{l}\text { Abnormal maternal whiteblood count } \\
>15,000 \times 10^{6} / \mathrm{L} / \text { no. tested }\end{array}$ & $55 / 70(79 \%)$ & $114 / 159(72 \%)$ & $1.37[0.85,2.23]$ & 0.20 \\
\hline Neonatal sepsis & $18(22 \%)$ & $30(14 \%)$ & $1.45[0.97,2.18]$ & 0.07 \\
\hline Placental Microbiology & $\mathrm{n}=30$ & $\mathrm{n}=85$ & & \\
\hline One or more isolates & II(37\%) & $30(35 \%)$ & $1.05[0.56,1.96]$ & 0.88 \\
\hline Group B Streptococcus & $4(13 \%)$ & $5(6 \%)$ & I.85 $[0.86,3.97]$ & 0.12 \\
\hline Escherichia coli & $6(20 \%)$ & $4(5 \%)$ & $2.35[1.27,4.34]$ & 0.01 \\
\hline Bacteroides/Prevotella spp. & $3(10 \%)$ & $5(6 \%)$ & I.54 $[0.62,3.84]$ & 0.35 \\
\hline Ureaplasma spp. & $3(10 \%)$ & $14(16 \%)$ & $0.66[0.23,1.90]$ & 0.44 \\
\hline Other isolates & $4(13 \%)$ & $15(18 \%)$ & $0.79[0.32,1.97]$ & 0.61 \\
\hline \multicolumn{5}{|l|}{ Placental histopathology } \\
\hline \multirow[t]{2}{*}{ Chorioamnionitis } & $\mathrm{n}=54$ & $n=150$ & & \\
\hline & $22(41 \%)$ & $56(37 \%)$ & $1.19[0.76,1.88)$ & 0.45 \\
\hline \multirow[t]{2}{*}{ Funisitis } & $\mathrm{n}=54$ & $\mathrm{n}=144$ & & \\
\hline & $14(26 \%)$ & $31(22 \%)$ & $1.35[0.83,2.21]$ & 0.23 \\
\hline
\end{tabular}

a $>37.5^{\circ} \mathrm{C}$ on two consecutive occasions

Indicators of clinical, histologic and microbiological chorioamnionitis are shown in Table 2. The incidence of both neonatal sepsis and elevated maternal C-reactive protein was higher among the cases. Placental histopathology was performed on $65 \%$ of cases and $73 \%$ of the subcohort while microbiology was available in $37 \%$ and $41 \%$ respectively. There was no difference in histopathologic evidence of infection between the two groups. Where microbiological examinations were performed, placental cultures were positive in $37 \%$ of cases and in $35 \%$ of the subcohort. Overall placental culture was positive in 54\% where histological chorioamnionitis was present and 23\% where it was absent. Although the percentage of chorioamnions with positive culture was similar between cases and subcohort, the types of microorganisms isolated from cases and subcohort members differed significantly. The most common chorioamnion isolate, Escherichia coli, was found in $20 \%$ of cases compared with $5 \%$ of the subcohort $(\mathrm{p}=0.01)$. Other micro-organisms prevalent in the cerebral palsy cases are listed in Table 2. Group B Streptococcus (GBS), the most common cause of early onset neonatal sepsis, was more frequent among cerebral palsy cases but the excess was not statistically significant. However, in the four cases with placental GBS, two also had $E$. coli, whereas in the five subcohort infants, only one had both GBS and E. coli. This study is underpowered, however, to identify small increases in risk for specific micro- organisms. Among the mothers with E. coli in the chorioamnion, clinical chorioamnionitis was found in one of six cases and none of four subcohort, and histological chorioamnionitis in two of four and one of two infants, respectively. Neonatal sepsis due to E. coli occurred in four infants, two cases and two subcohort.

\section{Discussion}

Our investigation explored the relationship between micro-organisms in the chorioamnion and cerebral palsy in survivors of preterm birth. This strategy provides the next step in identifying the causative pathway between infection and cerebral palsy. A previous report [17] of six children with cerebral palsy showed an association, that was not confirmed by our study, between coagulase negative staphylococci in the chorioamnion space and cerebral palsy. Of interest, in that study E. coli was isolated in the chorioamnion of $2 / 5(40 \%)$ cerebral palsy cases compared with $12 / 102(11.8 \%)$ controls; when we reanalysed their data we found an Odds Ratio of 5.00 (95\%CI [0.37, 47.36] $\mathrm{p}=0.13$ ).

The strength of this study is the investigation for specific micro-organisms in the chorioamnion using aseptic technique by trained scientists as part of routine hospital management of preterm births. Two important aspects of our study are: 1) the aseptic sampling method used to swab 
the chorio-amnionic membrane interface. It should be noted that if the maternal placental surface, instead of the sub-amnion, is swabbed, vaginal micro-organisms which contaminate the surface during removal, will be recovered; 2) the comprehensive microbiological culture methods used to recover aerobic and anaerobic bacteria, yeasts and genital mycoplasmas. These are costly and time-consuming but provide valuable information not obtainable in other ways. Furthermore, the study involved detailed five-year follow up of very low birthweight infants with near complete case ascertainment.

Some limitations of this study include: retrospective review of data collected for clinical management over a long period; lack of information about antenatal and postnatal steroid therapy; and lack of placental data on some subjects, which reduced the effective sample size for microbiological analysis to 30 cases and 85 subcohort. These data were available on a similar proportion of cases and the comparison sub-cohort. Although our hospital guidelines for the submission of placentas for pathological examination specify all placentas less than 34 weeks should be examined, for a variety of reasons, only a proportion of those placentas that meet the criteria for examination are actually submitted [18], a problem that is not unique to our institution [19-21]. Microbiological examination was not usually performed where there was a compelling reason for the preterm delivery, such as severe early onset pre-eclampsia. Nonetheless, it is possible that with a substantial level of missing data, a bias may have been introduced in the comparison of microbiological profiles between cases and the subcohort. Such bias could be responsible for the different associations observed between the small studies published to date. The 25\% positive culture rate from placentas without histochorioamnionitis is similar to other studies with comprehensive culture including genital mycoplasmas. Hillier et al found higher culture positive rates in preterm women (44\%) than term women without histological chorioamnionitis $(13 \%)[22]$. Two previous reports $[23,24]$ found $12 \%$ and $15 \%$ positive respectively but did not perform culture for genital mycoplasmas. In addition $29 \%$ of the latter study were at term. This study, nevertheless, has a number larger than most previously reported studies in such a population [7].

The strong association between threatened preterm labor and cerebral palsy is important to note and may have significant ramifications for obstetric management of threatened preterm labor. We postulate women with threatened preterm labour who do not deliver within a proximate time may be at significant risk of delivering an infant with cerebral palsy, perhaps through continuing fetal exposure to infection or activation of cytokines involved in the labor process.
In our study the presence of $E$. coli in the chorioamnion was significantly associated with cerebral palsy. This link is supported by experimental studies in a rabbit model, which showed that white matter damage in the fetal brain can be induced by E. coli amnionitis [11]. Histological chorioamnionitis was found in two of four $(50 \%)$ cases and one of two (50\%) subcohort with E. coli in the chorioamnion compared with 20/50 (40\%) and 55/149 (37\%) respectively in $E$. coli negative chorioamnions but this difference was not significant. However, histological chorioamnionitis may sometimes be absent and varies with the intensity and duration of infection [25].

In the light of the recent hypothesis [26] that bacterial vaginosis is associated with cerebral palsy, we analysed the data for Bacteroides spp. Although Bacteroides spp. were more common among cerebral palsy cases, this was not statistically significant. Although Ureaplasma spp. are generally the most common placental isolates found in chorioamnionitis, in our study Ureaplasma spp. were not more frequent among cerebral palsy cases. A recent study [27] linked $U$. urealyticum in placentas with chorioamnionitis and fetal vasculitis, but not in VLBW infants with cerebral echolucencies. This suggests that other organisms, such as E. coli, may be more important and that the reason histologic chorioamnionitis itself does not directly predict brain injury is because much of it is caused by $U$. urealyticum. Group B Streptococcus in the chorioamnion was twice as common in cases as in the subcohort; however, the long-standing hospital protocol of antibiotic prophylaxis in labor for group B Streptococcal carriers may have contributed to the lower total number of group B Streptococcal placental isolates.

In a study of 2646 women in labor, vaginal colonisation with $E$. coli was associated with preterm delivery and low birthweight [28]. These findings, together with our data linking E. coli and cerebral palsy, suggest the need for investigation and identification of $E$. coli in the genital tract in women with threatened preterm labor. The benefits and disadvantages of antibiotic therapy should then be considered.

\section{Conclusions}

This report of chorioamnionic E. coli infection in cerebral palsy cases gives insight into pathogenesis of infection and cerebral palsy and indicates the value of microbiological study of placentas in extremely preterm deliveries. Confirmation of our findings in a large prospective multicenter study is essential considering that this vital information may elucidate understanding of causative pathways for cerebral palsy.

\section{Competing interests}

None declared. 


\section{Authors' contributions}

$\mathrm{RV}$ conceived of the study, provided design input regarding cerebral palsy diagnosis, had oversight of medical record review, coordinated the study and drafted the manuscript.

SA contributed to the study design, identified study subjects from long-term database, abstracted medical records, entered data and conducted preliminary analyses

HM contributed to microbiological aspects of study design, interpretation of results and preparation of manuscript

YK contributed to hisopathological aspects of study design, review of placentae, interpretation of results and preparation of manuscript

JH contributed to epidemiological aspects of study design, design of data collection instruments and database, analysis plan, interpretation of results and preparation of manuscripts

\section{Acknowledgements}

We are grateful to K. Willson for statistical analysis. We thank J.S Robinson for advice and H.M Chambers for establishing a system of routine placental analysis, which has made this study possible. This study was supported by the Perinatal Pathology Research Fund of the Women's and Children's Hospital, Adelaide.

\section{References}

I. Stanley Fj: Survival and cerebral palsy in low birthweight infants: implications for perinatal care. Paediatr Perinat Epidemiol 1992, 6:298-310.

2. Kuban KCK, Leviton A: Cerebral Palsy. New Engl J Med 1994, 330:188-195

3. Alexander JM, Gilstrap LC, Cox SM, McIntire DM, Leveno KJ: Clinical chorioamnionitis and the prognosis for very low birthweight infants. Obstet Gynecol 1998, 91:725-729.

4. Baud O, Ville Y, Zupan V, Boithias C, Lacaze-Masmonteil T, Gabilan $\mathrm{JC}$ et al.: Are neonatal brain lesions due to intrauterine infection related to mode of delivery? Br J Obstet Gynaecol 1998, 105:121-I24.

5. Murphy DJ, Sellers S, MacKenzie IZ, Yudkin PL, Johnson AM: Casecontrol study of antenatal and intrapartum risk factors for cerebral palsy in very preterm singleton babies. Lancet 1995 , 346: $1449-1454$

6. O'Shea TM, Klinepeter KL, Meis PJ, Dillard RG: Intrauterine infection and the risk of cerebral palsy in very low birthweight infants. Paediatr Perinat Epidemiol 1998, I 2:72-83.

7. Wu YW, Colford JM Jr: Chorioamnionitis as a risk factor for cerebral palsy. A meta-analysis. JAMA 2000, 284: I4I7-I424.

8. Adinolfi M: Infectious diseases in pregnancy, cytokines and neurological impairment: an hypothesis. Dev Med Child Neurol 1993, 35:549-558.

9. Dammann $O$, Leviton A: Maternal intrauterine infection, cytokines, and brain damage in the preterm newborn. Pediatr Res 1997, 42:1-8.

10. Leviton A, Paneth N, Reuss ML, Susser M, Allred EN, Dammann O et al.: Maternal infection, fetal inflammatory response, and brain damage in very low birthweight infants. Pediatr Res 1999, 46:566-575.

II. Yoon BH, Kim CJ, Romero R, Jun JK, Park KH, Choi ST et al:: Experimentally induced intrauterine infection causes fetal brain white matter lesions in rabbits. Am J Obstet Gynecol 1997, I 77:792-802.

12. Wacholder S, Gail M, Pee D: Selecting an efficient design for assessing exposure-disease relationships in an assembled cohort. Biometrics 1991, 47:63-76.

13. McDonald HM, Chambers HM: Intrauterine infection and spontaneous mid-gestation abortion: Is the spectrum of microorganisms similar to that in preterm labour? Infect Dis Obstet Gynecol 2000, 8:220-227.

14. Khong TY: Swabbing placenta. [http://www.wch.sa.gov.au/lab medic/histopathology.html]. accessed 10 October 2002

15. Benirschke K, Kaufmann P: Infectious Diseases. In Pathology of the Human Placenta 4th edition. New York: Springer; 2000:59I-684.

16. Stanley F, Blair E, Alberman E: Pathways To Cerebral Palsy Involving Very Preterm Birth. In Cerebral Palsies Epidemiology \& Causal Pathways London: Mac Keith Press; 2000:60-82.

17. Mittendorf R, Covert R, Kohn J, Roizen N, Khoshnood B, Lee K-S: The association of coagulase-negative staphylococci isolated from the chorioamnion at delivery and subsequent development of cerebral palsy. J Perinatol 2001, 21:3-8.

18. Spencer MK, Khong TY: Conformity to guidelines for pathologic examination of the placenta. Arch Pathol Lab Med 2003, 127:205-207.

19. Booth VJ, Nelson KB, Dambrosia JM, Grether JK: What factors influence whether placentas are submitted for pathologic examination? Am J Obstet Gynecol 1997, 176:567-57I.

20. Badawi N, Kurinczuk JJ, Keogh JM, Chambers HM, Stanley FJ: Why is the placenta being ignored? Aust N Z J Obstet Gynaecol 2000, 40:343-346.

21. Wright C, Cameron H, Lamb W: A study of the quality of perinatal autopsy in the former northern region. The Northern Perinatal Mortality Survey Steering Group. Br J Obstet Gynaecol 1998, 105:24-28. 
22. Hillier SL, Martius J, Krohn M, Kiviat N, Holmes KK, Eschenbach DA: A case-control study of chorioamnionic infection and histologic chorioamnionitis in prematurity. New Engl J Med 1988, 3 I 9:972-978.

23. Zhang J, Kraus FT, Aquino Tl: Chorioamnionitis: A comparative histologic, bacteriologic, and clinical study. Int J Gynecol Pathol 1985, 4:1-10.

24. Pankuch GA, Appelbaum PC, Lorenz RP, Botti JJ, Schachter J, Naeye RL: Placental microbiology and histology and the pathogenesis of chorioamnionitis. Obstet Gynecol 1984, 64:802-806.

25. Singer D: Infection of fetuses and neonates. In Textbook of Fetal and Perinatal Pathology 2ndth edition. Edited by: Wigglesworth JS, Singer DB. Malden, Massachusetts: Blackwell Science; I998:454-5II.

26. Dammann $O$, Leviton $A$ : Does pre-pregnancy bacterial vaginosis increase a mother's risk of having a preterm infant with cerebal palsy? Dev Med Child Neurol 1997, 39:836-840.

27. Dammann O, Allred EN, Genest DR, Kundsin RB, Leviton A: Antenatal mycoplasma infection, the fetal inflammatory response and cerebral white matter damage in very-lowbirthweight infants. Paediatr Perinat Epidemiol 2003, 17:49-57.

28. Krohn MA, Thwin SS, Rabe LK, Brown Z, Hillier SL: Vaginal colonization by Escherichia coli as a risk factor for very low birthweight delivery and other perinatal complications. J Infect Dis 1997, |75:606-610.

\section{Pre-publication history}

The pre-publication history for this paper can be accessed here:

http://www.biomedcentral.com/1471-2393/4/1/prepub

Publish with Bio Med Central and every scientist can read your work free of charge

"BioMed Central will be the most significant development for disseminating the results of biomedical research in our lifetime. "

Sir Paul Nurse, Cancer Research UK

Your research papers will be:

- available free of charge to the entire biomedical community

- peer reviewed and published immediately upon acceptance

- cited in PubMed and archived on PubMed Central

- yours - you keep the copyright

Submit your manuscript here:

http://www.biomedcentral.com/info/publishing_adv.asp
BiolMedcentral 